\title{
Direct thrombin inhibitors: Patents 2002-2012 (Review)
}

\author{
$\mathrm{YI} \mathrm{KONG}^{1,3}, \mathrm{HAO} \mathrm{CHEN}^{1,2}$, YONG-QING WANG ${ }^{2}$, LING MENG $^{2}$ and JI-FU WEI ${ }^{2}$ \\ ${ }^{1}$ School of Life Science and Technology, China Pharmaceutical University, ${ }^{2}$ Research Division of Clinical Pharmacology, \\ The First Affiliated Hospital, Nanjing Medical University, ${ }^{3}$ State Key Laboratory of Natural Medicines, \\ China Pharmaceutical University, Nanjing, Jiangsu 210009, P.R. China
}

Received June 3, 2013; Accepted January 21, 2014

DOI: $10.3892 / \mathrm{mmr} .2014 .2025$

\begin{abstract}
Acute vascular diseases and other thromboses of the blood system constitute major health risks in developing countries. Thrombin plays a central role in blood coagulation, which is a crucial process involved in thrombosis. Direct thrombin inhibitors (DTIs) such as argatroban, dabigatran, dabigatran etexilate, lepirudin, desirudin and bivalirudin, which bind to thrombin and block its enzymatic activity, are widely and effectively used in the treatment of thromboembolic diseases. DTIs appear to overcome the disadvantages of indirect thrombin inhibitors such as unfractionated heparins (UFH). Although these DTIs show specific advantages over indirect inhibitors, they still present limitations, such as a narrow therapeutic window, and bleeding and anaphylaxis as side-effects. Novel anticoagulant drugs need thus to be developed to overcome these limitations. In the search for additional candidate agents with improved efficacy, safety and high bioavailability in oral administration, a high number of compounds has been identified, such as those derived from the tripeptide template D-Phe-Pro-Arg, aptamers and peptides isolated from blood-sucking animals. These candidates may prove the new agents of choice for the treatment of cardiovascular diseases.
\end{abstract}

\section{Contents}

1. Introduction

2. Direct thrombin inhibitors

3. Development of direct thrombin inhibitors

4. Discussion

Correspondence to: Dr Yi Kong, School of Life Science and Technology, China Pharmaceutical University, 24 Tongjia Street, Nanjing, Jiangsu 210009, P.R. China

E-mail: yikong668@163.com

Dr Ji-Fu Wei, Research Division of Clinical Pharmacology, The First Affiliated Hospital, Nanjing Medical University, 300 Guangzhou Road, Nanjing, Jiangsu 210009, P.R. China

E-mail: weijifu@hotmail.com

Key words: direct thrombin inhibitors, tripeptide, aptamer, blood-sucking animals

\section{Introduction}

Acute vascular diseases, such as myocardial infarction, stroke, pulmonary embolism (PE), deep vein thrombosis (DVT), atrial fibrillation (AF), peripheral arterial occlusion, and other thromboses of the blood system constitute major health risks. As of 2008, there were $\sim 2.3$ million people in the United States diagnosed with AF, a number estimated to increase to 5.6-10 million by 2050 . The incidence of hospital-acquired DVT is $\sim 10-40 \%$ among medical patients or those undergoing general surgery and $40-60 \%$ for those following major orthopedic surgery without prophylaxis. Moreover, $\sim 10 \%$ of deaths in the hospital are caused by PE. Vascular diseases are caused by either partial or total occlusion of a blood vessel by a thrombus, which contains fibrin and platelets. Blood coagulation is a crucial process involved in thrombosis (1).

Thrombin plays a central role in blood coagulation. It is a $\mathrm{Na}^{+}$-activated (2), trypsin-like serine protease, activated from a larger precursor protein (pro-thrombin). The active form of thrombin ( $\alpha$-thrombin) consists of a 36-amino acid light chain (A chain) and a 259-amino acid peptidase domain (B chain) covalently linked by a disulfide bridge (3). The active site of thrombin has three pockets: S1, S2 and S3. Pocket S1 contains an aspartic acid residue (Asp-189) at its bottom, which serves as the recognition site for the basic side chain. Pocket S2 occludes a hydrophobic pocket in the proximity of the Trp-60D residue; this pocket can accept larger aliphatic residues, such as valine and proline. Pocket S3 is flat and exposed to the solvent. Besides the active site, thrombin has two important regulatory regions, exosites 1 and 2. Exosite 1 was shown to be involved in the binding to fibrinogen, factor V, VIII, thrombomodulin and platelet protease-activated receptors (PARs), and exosite 2 was shown to be involved in the binding to factor V, VIII, platelet glycoprotein Ib $\alpha$ (GPIb $\alpha$ ) and heparin (4). Thrombin plays a central role in maintaining the integrity of hemostasis. It interacts with most of the zymogens and their cofactors, and plays both pro- and anticoagulant roles in the blood (Fig. 1). Thrombin activates platelets, leading to platelet aggregation. It converts fibrinogen into fibrin monomers, which spontaneously polymerize into fibrin polymers and activate factor XIII, a protein involved in fibrin cross-linking and clot stabilization. Thrombin also activates factor V and VIII in a positive feedback reaction (5). 


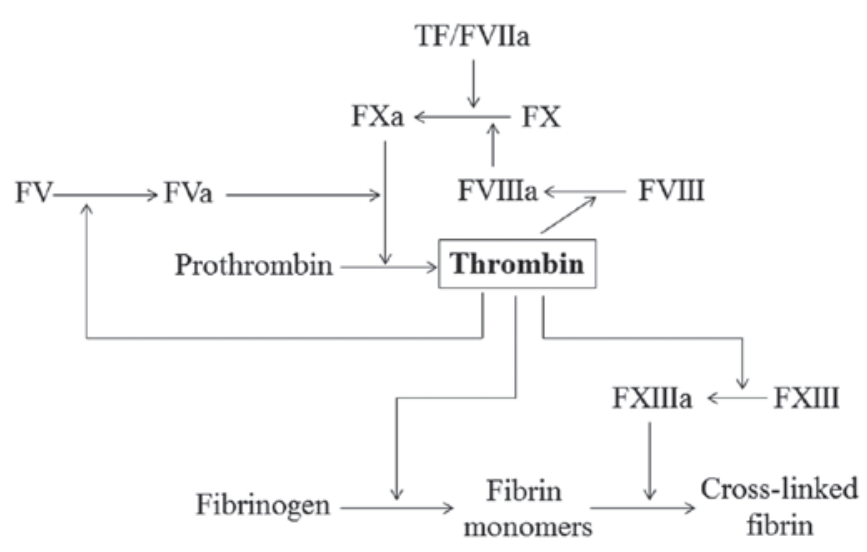

Figure 1. Interactions of thrombin in the coagulation system.

Anticoagulant therapy plays an essential role in the primary and secondary prevention of thromboembolic diseases (6). Unfractionated heparins (UFH), low molecular weight heparins (LMWH) and vitamin K antagonists (VKAs) are classified as indirect thrombin inhibitors. They have been widely and effectively used in certain cardiovascular and thromboembolic diseases for a number of years (7). However, their limitations are important and well-recognized. Heparins have to be parenterally administered and their activity requires cofactors such as anti-thrombin III. Moreover, their anticoagulant effects are variable due to non-specific protein binding, and therefore their dosage must be monitored by laboratory tests. In addition, treatment with heparins can cause a serious immune disorder known as heparin-induced thrombocytopenia (HIT) and can lead to osteoporosis in the long term. The main disadvantages of VKAs are the requirement of regular dose adjustments by monitoring of their anticoagulant effects; multiple food-drug and drug-drug interactions; severe intracranial and extracranial bleeding complications, and other severe side-effects such as coumarin-induced hepatitis (8). These limitations have led to the development of direct thrombin inhibitors (DTIs).

DTIs are agents that directly inhibit thrombin by binding to its active catalytic site and blocking its enzymatic activity. They have some advantages over the indirect agents: DTIs do not require cofactors to exert their effect; they can inhibit both soluble thrombin and fibrin-bound thrombin (9); they have an immediate onset of action and ideally affect only the target enzyme thus their anticoagulant effects are more predictable compared to those of heparins (7); DTIs can treat HIT instead of causing it and they are effective in cases where heparin treatment fails. These are some of the reasons for the widespread use of DTIs in the treatment of several acute vascular diseases.

\section{Direct thrombin inhibitors}

Argatroban. Argatroban (Fig. 2A) is a synthetic arginine-derived direct thrombin inhibitor that exerts a stronger anticoagulant effect compared to heparins and hirudins at equivalent levels. It is hepatically metabolized and predominantly eliminated through the biliary system (7). Dose adjustments are necessary in patients with hepatic, but not renal, impairment. The bioavailability of orally administered argatroban is negligible and therefore, it needs to be administered by infusion. Its half-life is $\sim 30 \mathrm{~min}$. Argatroban can be used as a parenteral anticoagulant for all cases where intravenous administration of heparin is prescribed. It was approved by the Food and Drug Administration (FDA) in 2000 for the treatment of HIT and interventional anticoagulation during percutaneous coronary intervention (PCI). An increased dosage can be used for a coronary artery bypass graft, and a lower dosage can be used for DVT treatment (10). Argatroban passes through endovascular and cellular barriers owing to its low molecular weight. It is therefore effective for the antithrombotic treatment of microvascular disorders (11).

Dabigatran. Dabigatran (Fig. 2B) is a synthetic benzamidine-derived direct thrombin inhibitor that rapidly and directly inhibits both free and fibrin-bound thrombin (7). It also exerts an inhibitory effect on thrombin-induced platelet aggregation and prevents the conversion of fibrinogen to fibrin. Dabigatran is metabolized by the glycoprotein system and eliminated through the kidneys (12). However, the absolute bioavailability of dabigatran after oral absorption is very low (6-7\%) (13). Dabigatran was the first anticoagulant approved by the FDA for primary prevention of ischemic stroke and systemic thromboembolism in patients without valvular atrial fibrillation (7).

Dabigatran etexilate. Dabigatran etexilate (Fig. 2C) is an orally administered direct thrombin inhibitor, developed to overcome the limited oral bioavailability of dabigatran. Once absorbed from the gastrointestinal tract, it is rapidly converted to the active form dabigatran. Bioconversion of dabigatran etexilate to dabigatran occurs in enterocytes, hepatocytes and the portal vein. Dabigatran circulates in the blood with a half-life of 12-17 h, which allows oral administration once a day. With a low potential for drug-drug interactions and a predictable anticoagulant effect, dabigatran etexilate can be administered in fixed doses without need for monitoring coagulation (14). In 2008, dabigatran etexilate was approved as a primary preventive agent for venous thromboembolic events (VTEs) in adult patients who underwent elective total hip or total knee replacement surgery in Europe. In October 2010, it was approved by the FDA to reduce the risk of stroke and systemic embolism in patients with non-valvular atrial fibrillation. However, this inhibitor is not currently indicated for treatment of any VTE in the USA (15).

Lepirudin and desirudin. Hirudin is isolated from the salivary glands of medicinal leeches, and has been used as an anticoagulant agent since 1909. Lepirudin and desirudin are two derivatives of hirudin. Lepirudin is composed of 65 amino acids that directly inhibit thrombin by simultaneously binding to its active site and to exosite 1 . Lepirudin is intravenously infused and its dosage is dependent on body weight. It is eliminated through the kidneys, which accounts for $\sim 90 \%$ of the systemic clearance. Lepirudin is licensed for the treatment of thrombosis complicating HIT. Moreover, unstable angina is an additional syndrome that lepirudin has the potential to treat (16).

Desirudin differs from lepirudin only in the first two $\mathrm{N}$-terminal amino acids. It is also eliminated through the kidneys, accounting for $90 \%$ of the systemic clearance. Desirudin reaches maximal plasma concentrations 1-3 $\mathrm{h}$ after 
<smiles>C[C@H]1CCNc2c1cccc2S(=O)(=O)N[C@@H](CCCNC(=N)N)C(=O)N1CC[C@@H](C)C[C@H]1C(=O)O</smiles>

B<smiles>Cn1c(CNc2ccc(C(=N)N)cc2)nc2cc(C(=O)N(CCC(=O)O)c3ccccn3)ccc21</smiles><smiles>CCCCCCOC(=O)/N=C(\N)c1ccc(NCc2nc3cc(C(=O)N(CCC(=O)OCC)c4ccccn4)ccc3n2C)cc1</smiles>

Figure 2. Structures of direct thrombin inhibitors (DTIs) (A) argatroban, (B) dabigatran and (C) dabigatran etexilate.

administration and has a terminal half-life of $2 \mathrm{~h}$. In 2010 , desirudin became the only FDA-approved fixed-dose subcutaneously administered DTI for the post-operative prevention of VTE in patients undergoing elective hip replacement surgery (17). Currently, desirudin is under investigation as a potential anticoagulant for HIT patients presenting or not thrombosis (3).

Bivalirudin. Bivalirudin is a synthetic analog of hirudin. It is a small polypeptide comprising 20 amino acids (D-PhePro-Arg-Pro-Gly-Gly-Gly-Gly-Asn-Gly-Asp-Phe-Glu-GluIle-Pro-Glu-Glu-Tyr-Leu). The N-terminal D-Phe-Pro-Arg-Pro region binds to the active site of thrombin with high affinity, and the C-terminal dodecapeptide Asn-Gly-Asp-Phe-GluGlu-Ile-Pro-Glu-Glu-Tyr-Leu binds to exosite 1 of thrombin (18). Bivalirudin exhibits a short half-life (25 min), predominantly non-renal metabolism, and low immunogenicity. It achieves peak plasma concentration within 2 min of intravenous bolus injection. Bivalirudin is primarily used for the treatment of percutaneous transluminal coronary angioplasty, the most frequent type of PCI. It is also indicated for PCI when provisional therapy with the GPIIb/IIIa antagonist is employed, and for patients with HIT or HIT with thrombosis syndrome (HITTS) undergoing PCI (19).

\section{The development of direct thrombin inhibitors}

Alhough these DTIs show specific advantages compared to indirect thrombin inhibitors, they still have limitations such as a narrow therapeutic window, and bleeding and anaphylaxis as side-effects. Approximately $80 \%$ of circulating dabigatran is eliminated through the kidneys in a manner that its plasma concentrations increase in renal insufficiency. Consequently, it is contraindicated in patients with renal failure (20). Argatroban and hirudins require dose adjustment guided by monitoring of their anticoagulant effect (8). Lepirudin may associate with anaphylaxis, while another significant limitation of this compound is its narrow therapeutic window (21). The main clinical disadvantage of bivalirudin is that it has no known antidote. Desirudin is associated with antibody formation in $10 \%$ of recipients, although these antibodies do not appear to be inhibitory as desirudin potency is not affected by their presence (22). Although these specific disadvantages can be serious, the main and common disadvantage of all DTIs is the risk of bleeding.

These limitations have prompted the search for new anticoagulant drugs, which ideally, would be orally available, present no bleeding complications, and have a suitable half-life.

Low molecular weight thrombin inhibitor candidates. Previous studies have suggested that thrombin inhibitors that contain the tripeptide template D-Phe-Pro-Arg (P3-P2-P1), such as argatroban and dabigatran, are the most effective $(23,24)$. This tripeptide can bind to multiple amino acids at the thrombin active site. It can bind to arginines, especially the positively-charged guanidine group interacting with the Asp-189 residue at the bottom of the S1 pocket. Hydrophobic amino acids, such as proline in the $\mathrm{P} 2$ position, can bind to the $\mathrm{S} 2$ pocket, and aromatic groups in the $\mathrm{P} 3$ position can interact with the lipophilic and aromatic fragments of the S3 pocket (25).

Typically, DTIs possess a P1 group that fills the specific S1 pocket. Generally, to produce potent inhibitors, the P1 ligand features a strongly basic functional group such as guanidine (argatroban), alkylamine, amidine, benzamidine (dabigatran), or 4-aminopyridine (26). Patents WO00/42059 (27), US2007/0249578 A1 (28) and US2010/0087651 Al (29) disclosed a series of compounds in which the $\mathrm{P} 1$ position was replaced with amidino, benzamidine, or their analogs. For example, compound 1 (Fig. 3), derived from formula 1 (Fig. 3), has an $\mathrm{IC}_{50}$ of prothrombin time (PT) $<0.02 \mu \mathrm{M}$, and an $\mathrm{IC}_{50}$ of activated partial thromboplastin time (APTT) $<1 \mu \mathrm{M}$. Compounds containing strongly basic amines in the $\mathrm{P} 1$ position have poor oral absorption properties and poor pharmacokinetics, because the basic amines are protonated at the $\mathrm{pH}$ of the intestinal tract.

Strategies to overcome these shortcomings include the use of a prodrug with a masked, weakly basic or non-basic, P1 group, such as dabigatran etexilate (30). N-hydroxylated derivatives 
<smiles>[R]CNC(=O)C1CN1C(=O)C([R])c1ccc[Y]([R])c1</smiles><smiles>[R]C(=O)N(Cc1cccc([R])c1)NS([R])(=O)=O</smiles><smiles>CC(C)CCS(=O)(=O)NN(Cc1cccc(/C(N)=N/O)c1)C(=O)N1CCCCCC1</smiles>

Formula 2<smiles>O=C(NCc1cc(Cl)ccc1-n1cnnn1)[C@@H]1CC=NN1C(=O)[C@@H](O)c1ccc(F)cc1</smiles><smiles>CCC(=O)O[C@@H](C(=O)N1N=CC[C@H]1C(=O)NCc1cc(Cl)ccc1-n1cnnn1)c1ccc(F)cc1</smiles>

Compound 3A

Compound 3B<smiles>O=C(Cn1c(Cl)cnc(NCC(F)(F)c2ccccn2)c1=O)NCc1ncccc1F</smiles>

Compound 4

Figure 3. Structures of thrombin inhibitor candidates from tripeptide templates.

such as amidoxime and benzamidoxime, are less basic because of the introduced oxygen atom. They are not protonated under physiological conditions and are expected to have sufficient oral absorption, and therefore, improved bioavailability (31). Patent US2008/0004256 A1 (32) disclosed a series of compounds derived from formula 2 (Fig. 3). Compound 2 (Fig. 3), where the $\mathrm{P} 1$ position is replaced by benzamidoxime, is the most bioavailable of these compounds. The inhibition constant (Ki) values for thrombin and trypsin are 0.59 and $32.23 \mu \mathrm{M}$, respectively, for this compound. Azoles $(26,33)$ (such as imidazoles, aminothiazoles and $\mathrm{N}$-acetamidoimidazole) and aryl heterocycles (pyridines, pyrazinones, piperidines and pyridinones) are also weakly basic groups. When they are incorporated into the P1 position, the resulting peptides exhibit very good selectivity for thrombin vs. trypsin and lower in vivo toxicity.

A recent study (25) demonstrated that the P1 fragment of the inhibitor does not need to contain a highly basic functional group to efficiently inhibit thrombin. The chlorophenyl fragment in the P1 position can be deeply inserted into the S1 pocket of the thrombin active site (25). In addition, heterocycle-substituted chlorophenyl incorporated into the P1 group was shown to provide more potent inhibitors (34). Patent US8119673 B2 (35) disclosed and described 57 D-PhePro-Arg derivatives with heterocycle-substituted chlorophenyl incorporated into the $\mathrm{P} 1$ position, along with their synthetic routes. Compounds $3 \mathrm{~A}$ and $3 \mathrm{~B}$ (Fig. 3) were claimed in this patent. Their $\mathrm{IC}_{50}$ values are 4 and $120 \mathrm{nM}$, respectively, according to a chromogenic robotic assay.

The $\mathrm{P} 2$ position of the tripeptide is important, not only in relation to its thrombin inhibitory activity, but also in relation to the oral bioavailability. In previous studies, it was found that using dehydroproline to replace the proline of the tripeptide slightly increases the in vitro potency, in vivo activity, and oral bioavailability (36), replacing it with 4-fluoroproline increased the oral bioavailability (34) and replacing it with a pyrazinone ring increased both activity and oral 


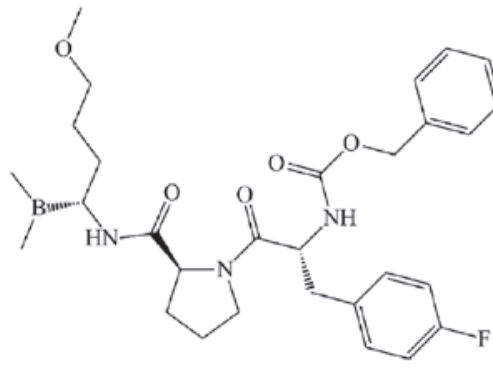

Compound 5<smiles>CN1C(=O)[C@@H](Cc2ccc(C(=N)N)cc2)Oc2cc(N(Cc3ccccc3)C(=O)CC(=O)O)ccc21</smiles>

Compound 6<smiles>[R]OC(=O)/N=C(\N)c1ccc(NCc2nc3cc(C(=O)N(CCC(=O)OCc4nc(C)c(C)nc4C)c4ccccn4)ccc3n2C)cc1</smiles>

Formula 3<smiles>CCCCCCCCCCCCCC(=O)N[C@@H](CCCNC(=N)N)C(=O)ONC(Cc1ccccc1)C(=O)OC</smiles>

Myr-D-Arg-D-Phe-OMe

Figure 4. Structures of thrombin inhibitor candidates from non-classic tripeptide templates.

bioavailability (37). For example, compound 4 (Fig. 3), first described in patent US6455532 B1 (38), is a potentially new thrombin inhibitor with 3-aminopyrazinone in the P2 position. It inhibited thrombin activity with a $\mathrm{Ki}$ of $5.2 \mathrm{nM}$. The 3 -aminopyrazinone in the $\mathrm{P} 2$ position of compound 3 played a crucial role in thrombin inhibition by forming an hydrogen bond with Gly-216 of thrombin. However, it was less resistant to oxidative metabolism. Researchers from Merck Research Laboratories found that 2-aminopyridine $\mathrm{N}$-oxide in the P2 position confers reduced metabolic liability compared to that of pyrazinones (39).

Derivatives of organoboronic acids exhibit thrombin inhibitory activity. Patent US20070185060 A1 (40) disclosed a series of organoboronic acid compounds such as compound 5 (Fig. 4). This compound has thrombin inhibitory activity with an $\mathrm{IC}_{50}<0.1 \mu \mathrm{m}$. It has a neutral aminoboronic acid residue, which can bind thrombin $\mathrm{S} 1$, linked to a hydrophobic moiety, which can bind thrombin S2 and S3. 1,4-Benzoxazine-3(4H)-one was found to be a suitable scaffold for a thrombin inhibitor. Compound 6 (Fig. 4), which was derived from this scaffold, is a highly potent and selective thrombin inhibitor with $\mathrm{Ki}$ of $2.6 \mathrm{nM}$ for thrombin and 112,400 -fold selectivity for trypsin. Due to the presence of the benzamidine moiety, it has considerable potential to show improved bioavailability and be developed as an orally active prodrug (41). Compounds derived from formula 3 (Fig. 4) are a series of non-peptide thrombin inhibitors that are described in patent WO2012/174865 A1 (42). These compounds have higher thrombin inhibitory activities compared to dabigatran etexilate. Non-classic tripeptide templates such as Tos-PheArg-OCH $\mathrm{OCH}_{3}$ and X-D-Arg-D-Phe-OMe can also act as thrombin inhibitors. When $\mathrm{X}$ is replaced by myristic acid, the compound (Fig. 4) has high activity in thrombin inhibition $(\mathrm{Ki}=0.17 \mu \mathrm{M})$ and high selectivity towards thrombin in comparison to factor X, plasmin, and trypsin (>600-, 900- and 5,000-fold, respectively) (43).

Aptamers are 15-40 nucleotide, single-stranded DNA or RNA molecules forming three-dimensional structures that bind to their molecular targets with affinity and specificity $(44,45)$. Due to their high binding affinities for target macromolecules, aptamers can act as inhibitors (46). ARC-183, or HD1, is a 15-nucleotide DNA molecule discovered in the 1990s. It is a strong anticoagulant in vitro, and inhibits the thrombin-catalyzed activation of fibrinogen and thrombininduced platelet aggregation by binding to exosite 1. Despite its high affinity $(\mathrm{Kd}=30 \mathrm{nM})$, it has a short half-life $(2.5 \mathrm{~min})$. In order to overcome this disadvantage, another DNA aptamer (NU172) was developed. This aptamer binds to thrombin with a Kd of $100 \mathrm{pM}$ and has a half-life of $25 \mathrm{~min}$ when tested in pigs. Toggle-25 is a 25-nucleotide RNA aptamer that contains 2'-fluoropyrimidine nucleotides selected to bind exosite 2 of thrombin with high specificity and affinity $(\mathrm{Kd}=2 \mathrm{nM})(47)$. Other thrombin inhibitors, such as the DNA aptamer RE31 (48), the RNA aptamer HD22 (49), and R9D-14 (50) were also identified. These aptamers possess properties that render them especially suitable for use as thrombin inhibitors: 
they typically exhibit high affinity and specific binding to the target protein, and demonstrate little to no toxicity or immunogenicity (51).

Derivatives of natural substances. The widely used in the clinic anticoagulant drugs such as hirudin and its analog lepirudin were isolated from blood-sucking leeches. For these animals to feed on blood from mammalian hosts, they need to prevent local clotting of the host's blood. These parasites have developed various anti-clotting mechanisms, including the specific inhibition of thrombin (52). In addition to hirudin, which was first described in 1884 (53), other thrombin inhibitors such as haemadin, bufrudin and theromin have been isolated from various species of leeches (54). Haemadin is a slow, tight-binding thrombin inhibitor isolated from the species Haemadipsa sylvestris with an apparent molecular mass of $5 \mathrm{kDa}$. It exhibits a $\mathrm{Ki}$ as low as $100 \mathrm{fM}$ (55). Bufrudin was isolated from the species Hirudinaria manillensis and has $66 \%$ sequence homology with hirudin, indicating that it acts as a similar inhibitor (56). Theromin, isolated from the gut leech Theromyzon tessulatum, is the most potent inhibitor (Ki of 12 vs. $21 \mathrm{fM}$ for hirudin). It is a homodimer of 67 amino acid residues with 16 cysteines engaged in eight disulfide bridges (57).

Additional agents targeting thrombin were obtained from various hematophagous animals such as mosquitoes, ticks, and insects. Mosquito saliva carries a high number of factors with anticoagulant activities. Anophelin is a peptide with a molecular weight of $6.5 \mathrm{kDa}$, isolated from the salivary glands of the mosquito species Anopheles albimanus. It inhibits thrombin with an $\mathrm{IC}_{50}$ of $45 \mathrm{nM}$ and binds to both the active site and exosite 1 (58). An additional peptide of $45 \mathrm{kDa}$ was identified and isolated from the salivary glands of the malarial vector mosquito Anopheles stephensi. It inhibits thrombin only by binding to the active site (59). AaTI is another peptide from the mosquito Aedes aegypti, which inhibits thrombin by binding to exosite 2 (60).

A few potential thrombin inhibitors were also isolated from ticks. Boophilin is a novel $20 \mathrm{kDa}$ thrombin inhibitor isolated from the cattle tick Boophilus microplus. It inhibits thrombin with a $\mathrm{Ki}$ of $57 \mathrm{pM}$ by binding to the active site and exosite 1 (61). Boophilin is composed of two canonical Kunitz domains, which inhibit not only thrombin, but also, other serine proteases (62). Microphilin is the smallest salivary thrombin inhibitor peptide known to date, with a molecular weight of $1.7 \mathrm{kDa}$. It was also isolated from the cattle tick Boophilus microplus. Microphilin inhibits thrombin in a dosedependent manner with an $\mathrm{IC}_{50}$ of $5.5 \mu \mathrm{M}(63)$. From the midgut of the parthenogenetic tick species Haemaphysalis longicornis (Ixodidae), another thrombin inhibitor was isolated, known as hemalin. It contains two Kunitz domains and has high homology to boophilin. Hemalin inhibits thrombin in a dose-dependent manner with a $\mathrm{Ki}$ of $0.25 \mu \mathrm{M}$. It also inhibited both thrombin-induced fibrinogen clotting and thrombininduced platelet aggregation (64). From the same species, two additional proteins that inhibit thrombin by binding to exosite 1 were identified, madanin 1 and 2 (65).

Other thrombin inhibitors such as triabin, infestin, brasiliensin and dipetalogastin were identified and isolated from blood-sucking insects. Triabin was purified from the saliva of Triatoma pallidipennis (66). Infestin was isolated from midguts of Triatoma infestans (67). Brasiliensin was identified and isolated from Triatoma brasiliensis (68). Dipetalogastin was found and isolated from Dipetalogaster maximus (69).

Besides these blood-sucking animals, other natural sources of compounds targeting thrombin include snake and wasp venom, and skin secretions of toads. TTI-Nh is a new $14.3-\mathrm{kDa}$ protein isolated from venom of the cobra species Naja haje, and consisting of a single polypeptide chain with 14 cysteine residues that form seven intramolecular disulfide bridges. It inhibits thrombin with an $\mathrm{IC}_{50}$ of $73 \mathrm{nM}$ without any cytotoxic side-effects (70). Bothrojaracin is a $27-\mathrm{kDa}$ anticoagulant protein isolated from the venom of the viper Bothrops jararaca. It inhibits thrombin by binding to exosites 1 and 2 (71). Bicolin was purified and characterized from the venom of wasps. It showed inhibitory activity against trypsin and thrombin (72). BMSI-1 is a serine protease inhibitor identified from skin secretions of the toad Bombina microdeladigitora. It inhibits trypsin and thrombin with a $\mathrm{Ki}$ of 0.02 and $0.15 \mu \mathrm{M}$, respectively. Furthermore, the activity of BMSI-1 was not lost after incubation in boiling water for $10 \mathrm{~min}$, indicating that BMSI-1 is a thermally highly stable inhibitor (73).

Natural flavonoids such as myricetin and quercetin (Fig. 5) were discovered to act as thrombin inhibitors, but with low activity. The $\mathrm{IC}_{50}$ of TT is 0.006 and $0.035 \mathrm{mM}$ for myricetin and quercetin, respectively (74). Glycerolipids, especially the diacylglycerophospholipids isolated from the fungus Stereum hirsutum, can inhibit thrombin by binding to its active site (75). Scutellarin (Fig. 5), the major anti-oxidant in breviscapine extracted from the plant species Erigeron breviscapus, was clinically effective in treating acute cerebral infarction and paralysis induced by cerebrovascular diseases. However, it has certain disadvantages, such as low solubility in water and low bioavailability. Scutellarein (Fig. 5), the hydrolyzed product and metabolic form of scutellarin, was used to design and synthesize derivatives with improved biological activity and water solubility. Many of these derivatives, especially the morpholinyl aminomethylene substituent, showed stronger anticoagulant activity and higher solubility in water (76). A recent study identified thrombin inhibitors isolated from the freshwater cyanobacterium Anabaena compacta. These molecules, known as spumigin $\mathrm{J}$ and A (Fig. 5), inhibited thrombin with $\mathrm{EC}_{50}$ values of 4.9 and $2.1 \mu \mathrm{M}$, respectively. In addition, the two compounds showed higher inhibitory activity against cathepsin $\mathrm{B}$, with $\mathrm{EC}_{50}$ values of 0.7 and $0.2 \mu \mathrm{M}$, respectively (77). Chlorodysinosin A, dysinosin A and oscillarin (Fig. 5), three natural products that belong to the aeruginosin family of serine protease inhibitors, exhibit low inhibitory activity against thrombin in vitro $\left(\mathrm{IC}_{50}=5.8,46\right.$ and $28 \mathrm{nM}$, respectively). These molecules inhibit thrombin owing to their hydrophobic interactions with the S3 site of thrombin (78).

\section{Discussion}

Thrombotic diseases are major causes of mortality and morbidity in the industrial world. Thrombin, which plays an important role in blood coagulation, is a key cause of thrombotic diseases. Indirect thrombin inhibitors such as heparins and VKAs are widely used in the treatment of 
<smiles>O=c1c(O)c(-c2ccc(O)c(O)c2)oc2cc(O)cc(O)c12</smiles>

Quercetin<smiles>O=c1c(O)c(-c2cc(O)c(O)c(O)c2)oc2cc(O)cc(O)c12</smiles>

Myricetin<smiles>O=C(O)C1(CO)C(O)COCC1Cc1cc2oc(-c3ccc(Cl)cc3)cc(=O)c2c(O)c1O</smiles>

Scutellarin<smiles>O=c1cc(-c2ccc(O)cc2)oc2cc(O)c(O)c(O)c12</smiles>

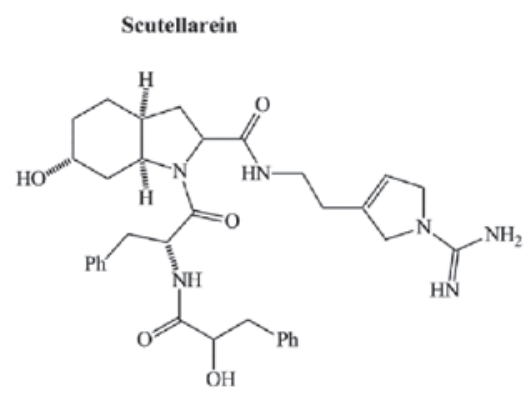

Oscillarin<smiles>COC1C2CC(C)CC(C2C(=O)N(C)C(C)CCCCN)N1C(=O)C(CCc1ccc(O)cc1)NC(=O)C(O)Cc1ccc(O)cc1</smiles>

Spumigin J<smiles>C[C@@H]1C[C@@H](C(=O)N[C@@H](CCCNC(=N)N)C(=O)O)N(C(=O)[C@H](CCc2ccc(O)cc2)NC(=O)[C@H](O)Cc2ccc(O)cc2)C1</smiles>

Spumigin A

$\mathbf{R}=\mathbf{C l}$, Chlorodysinosin A

$\mathbf{R}=\mathbf{H}$, Dysinosin A

Figure 5. Structures of thrombin inhibitor candidates from natural substances.

thrombotic diseases despite their serious disadvantages. DTIs were developed as potential drugs allowing to overcome these disadvantages while still maintaining pharmacological activity.

In this review, we briefly summarized the advantages and disadvantages of DTIs. These agents have several advantages over indirect ones, such as direct inhibition of free and clot-bound thrombin, lack of required cofactors, more predictable anticoagulant response, and the fact that they do not cause immune-mediated thrombocytopenia. Despite their effective clinical use, they have some adverse effects. Bleeding is the side-effect of almost all anti-thrombotic agents. Eliminating or reducing the bleeding may be the aim of future studies. There are currently no DTI-specific antidotes that show potential to reduce bleeding, therefore developing such drugs is also a desired direction for future research. For example, an aptamer termed JPB5 was shown to act as an antidote, thus providing a superior safety profile for bivalirudin (79). In addition to bleeding, some DTIs have a narrow therapeutic window, making it is necessary to adjust the dose by monitoring their anticoagulant effect. This is another issue that needs to be solved in the future. Additionally, future exploration of additional effects of these new agents is necessary. For example, dabigatran etexilate can be also used to treat cerebral venous thrombosis (80).

In the search for new direct thrombin inhibitors, many candidate compounds were discovered. Compounds based on the amino acid sequence Phe-Val-Arg (P3-P2-P1) were confirmed to be effective inhibitors. Argatroban, the derivative of arginine, and dabigatran, the derivative of benzamidine, are used effectively in the clinic. However, these derivatives were found to have low oral bioavailability and cytotoxicity. New direct thrombin inhibitors with improved properties need thus to be discovered or developed.

Aptamers have a few advantages such as high affinity and complete absence of toxicity and immunogenicity, which renders their use in pharmacological therapy an attractive approach. For example, pegaptanib is an aptamer that binds to the vascular endothelial growth factor (VEGF) and inhibits its biological activity. This aptamer was recently approved 
for therapeutic use for the treatment of age-related macular degeneration (81). Aptamers that inhibit thrombin in different developmental stages may also represent a powerful approach in antithrombotic therapies.

Hirudin is a well-known thrombin-inhibitory agent, first isolated from a blood-sucking animal. The finding of this compound inspired the search for new thrombin inhibitors, and numerous active agents against thrombin have been identified thereafter, isolated from blood-sucking animals such as mosquitos, ticks and bugs. These animals are so small in size that it is difficult to directly obtain active compounds from these, therefore genetic engineering is required to produce active thrombin-inhibitory agents. Some analogs and derivatives of natural compounds also exhibit inhibitory activity, such as the derivatives of hirudin, lepirudin and desirudin. High numbers of analogs or derivatives are expected to emerge from ongoing investigations. In addition, a few small molecular compounds isolated from plants and bacteria showed thrombin-inhibitory activity. Traditional Chinese medicine (TCM) has been employed for decades in the treatment of thrombotic diseases. Previous studies $(82,83)$ have identified a number of compounds with thrombin-inhibitory activity isolated from medicine administered in TCM. Future studies on these TCM drugs may lead to the finding of new thrombin inhibitors.

\section{Acknowledgements}

This project was sponsored by grants from the National Natural Science Foundation of China (nos. 30972822, 81273274, 81273375 and 81273593), the Priority Academic Program Development of Jiangsu Higher Education Institutions, National Major Scientific, Technological Special Project for 'Significant New Drugs Development' (no. 2011ZX09302-003-02), the Jiangsu Province Major Scientific and Technological Special Project (no. BM2011017) and the Jiangsu Provincial Qing Lan Project.

\section{References}

1. Baldo L, Plent S, Skerjanec S and Meanwell C: Novel use of bivalirudin in the treatment of acute coronary syndrome. US Patent 20090247465 A1. Filed March 27, 2009; issued October 1, 2009.

2. Di Cera E: Thrombin. Mol Aspects Med 29: 203-254, 2008.

3. Nar H: The role of structural information in the discovery of direct thrombin and factor Xa inhibitors. Trends Pharmacol Sci 33: 279-288, 2012.

4. Bock PE, Panizzi P and Verhamme I: Exosites in the substrate specificity of blood coagulation reactions. J Thromb Haemost 5: 81-94, 2007.

5. Gustafsson D: Combinations comprising a low molecular weight thrombin inhibitor and a prodrug of a low molecular weight thrombin inhibitor. US Patent 20080113960 A1. Filed November 9, 2007; issued May 15, 2008.

6. Robert S, Ghiotto J, Pirotte B, et al: Is thrombin generation the new rapid, reliable and relevant pharmacological tool for the development of anticoagulant drugs? Pharmacol Res 59: 160-166, 2009

7. Lee CJ and Ansell JE: Direct thrombin inhibitors. Br J Clin Pharmacol 72: 581-592, 2011.

8. Harenberg J, Marx S, Krejczy M and Wehling M: New anticoagulants-promising and failed developments. Br J Pharmacol 165 : 363-372, 2012.

9. Nutescu EA and Wittkowsky AK: Direct thrombin inhibitors for anticoagulation. Ann Pharmacother 38: 99-109, 2004.

10. Fareed J and Jeske WP: Small-molecule direct antithrombins: argatroban. Best Pract Res Clin Haematol 17: 127-138, 2004.
11. Owoo G and Burgos RA: Argatroban formulations and methods for making and using same. US Patent 7915290 B2. Filed February 29, 2008; issued March 29, 2011.

12. Blech S, Ebner T, Ludwig-Schwellinger E, Stangier J and Roth W: The metabolism and disposition of the oral direct thrombin inhibitor, dabigatran, in humans. Drug Metab Dispos 36: 386-399, 2008

13. Fugate JE, Rabinstein AA, McBane RD and Lanzino G: Dabigatran: a primer for neurosurgeons. World Neurosurg 79: 154-158, 2013.

14. Franchini M and Mannucci PM: A new era for anticoagulants. Eur J Intern Med 20: 562-568, 2009.

15. Eriksson BI, Smith H, Yasothan U and Kirkpatrick P: Dabigatran etexilate. Nat Rev Drug Discov 7: 557-558, 2008.

16. Greinacher A and Lubenow N: Recombinant hirudin in clinical practice: focus on lepirudin. Circulation 103: 1479-1484, 2001.

17. Frame JN, Rice L, Bartholomew JR and Whelton A: Rationale and design of the PREVENT-HIT study: a randomized, open-label pilot study to compare desirudin and argatroban in patients with suspected heparin-induced thrombocytopenia with or without thrombosis. Clin Ther 32: 626-636, 2010.

18. Gosselin RC, Dager WE, King JH, et al: Effect of direct thrombin inhibitors, bivalirudin, lepirudin, and argatroban, on prothrombin time and INR values. Am J Clin Pathol 121: 593-599, 2004.

19. Warkentin TE: Bivalent direct thrombin inhibitors: hirudin and bivalirudin. Best Pract Res Clin Haematol 17: 105-125, 2004.

20. Gross PL and Weitz JI: New anticoagulants for treatment of venous thromboembolism. Arterioscler Thromb Vasc Biol 28: 380-386, 2008.

21. Greinacher A, Lubenow N and Eichler P: Anaphylactic and anaphylactoid reactions associated with lepirudin in patients with heparin-induced thrombocytopenia. Circulation 108: 2062-2065, 2003.

22. Lewis CM and Deschler DG: Desirudin reduces the rate of microvenous thrombosis in a rat model. Laryngoscope 118: 1149-1152, 2008.

23. Blombäck B, Blombäck M, Olsson P, Svendsen L and Aberg G: Synthetic peptides with anticoagulant and vasodilating activity. Scand J Clin Lab Invest Suppl 107: 59-61, 1969.

24. Costanzo MJ, Maryanoff BE, Hecker LR, et al: Potent thrombin inhibitors that probe the S1 subsite: tripeptide transition state analogues based on a heterocycle-activated carbonyl group. J Med Chem 39: 3039-3043, 1996.

25. Kudryavtsev K, Shulga D, Chupakhin V, et al: Design of small-molecule thrombin inhibitors based on the cis-5-phenylproline scaffold. Russ Chem Bull Int Ed 60: 685-693, 2011.

26. Isaacs RC, Solinsky MG, Cutrona KJ, et al: Structure-based design of novel groups for use in the P1 position of thrombin inhibitor scaffolds. Part 1: Weakly basic azoles. Bioorg Med Chem Lett 16: 338-342, 2006.

27. Inghardt $T$ and Nystrm JE: Amidinobenzylamine derivatives and their use as thrombin inhibitors. US Patent 6599894. PCT Pub No. WO00/42059. Filed January 13, 2000; issued July 29, 2003.

28. Inghardt T, Karlsson O, Linschoten M and Nystrom JE: New amidino derivatives and their use as thrombin inhibitors. US Patent 20070249578 A1. Filed June 6, 2007; issued October 25, 2007.

29. Inghardt T, Johansson A and Svensson A: New mandelic acid derivatives and their use as thrombin inhibitors. US Patent 20100087651 Al. Filed June 25, 2009; issued April 8, 2010.

30. Kreutter KD, Lu T, Lee L, et al: Orally efficacious thrombin inhibitors with cyanofluorophenylacetamide as the P2 motif. Bioorg Med Chem Lett 18: 2865-2870, 2008.

31. Zega A, Mlinšek G, Šolmajer T, Trampuš-Bakija A, Stegnar M and Urleb U: Thrombin inhibitors built on an azaphenylalanine scaffold. Bioorg Med Chem Lett 14: 1563-1567, 2004.

32. Urleb U, Zega A, Stegnar M, Trampus BA, Solmajer T and Mlinsek G: Amidinophenylalanine derivatives as thrombin inhibitors. US Patent 20080004256 A1. Filed September 12, 2007; issued January 3, 2008.

33. Isaacs RC, Solinsky MG, Cutrona KJ, et al: Structure-based design of novel groups for use in the P1 position of thrombin inhibitor scaffolds. Part 2: N-acetamidoimidazoles. Bioorg Med Chem Lett 18: 2062-2066, 2008.

34. Staas DD, Savage KL, Sherman VL, et al: Discovery of potent, selective 4-fluoroproline-based thrombin inhibitors with improved metabolic stability. Bioorg Med Chem Lett 14: 6900-6916, 2006.

35. Brånalt J, Gustafsson D, Nilsson I and Polla M: Compounds 148. US Patent 8119673 B2. Filed June 23, 2009; issued February 21, 2012. 
36. Lange UE, Baucke D, Hornberger W, Mack H, Seitz W and Höffken HW: Orally active thrombin inhibitors. Part 2: Optimization of the P2-moiety. Bioorg Med Chem Lett 16: 2648-2653, 2006.

37. Young MB, Barrow JC, Kristen L, et al: Discovery and evaluation of potent P1 aryl heterocycle-based thrombin inhibitors. J Med Chem 47: 2995-3008, 2004.

38. Burgey CS, Robinson KA, Williams PD, Coburn C, Lyle TA and Sanderson PE: Pyrazinone thrombin inhibitors. US Patent 6455532 B1. Filed June 1, 2000; issued September 24, 2002.

39. Nantermet PG, Burgey CS, Robinson KA, et al: P2 pyridine N-oxide thrombin inhibitors: a novel peptidomimetic scaffold. Bioorg Med Chem Lett 15: 2771-2775, 2005.

40. Wang S: Boronic acid thrombin inhibitors. US Patent 20070185060 A1. Filed March 9, 2005; issued August 9, 2007.

41. Ilaš J, Tomašić T and Kikelj D: Novel potent and selective thrombin inhibitors based on a central 1,4-benzoxazin-3(4H)-one scaffold. J Med Chem 51: 2863-2867, 2008

42. Xu Y, Yang X, Gong G, Yang W, He G and Li F: Oral thrombin inhibitor and preparation method and medical use thereof. WIPO Patent 2012174856 A1. Filed June 15, 2012; issued December 27, 2012.

43. Poyarkov AA, Poyarkova SA, Smirnova IV and Kukhar VP: Liporetro-D-peptides-a novel class of highly selective thrombin inhibitors. Thromb Res 129: 97-105, 2012.

44. Burke JM and Berzal-Herranz A: In vitro selection and evolution of RNA: applications for catalytic RNA, molecular recognition, and drug discovery. FASEB J 7: 106-112, 1993.

45. Bock LC, Griffin LC, Latham JA, Vermaas EH and Toole JJ: Selection of single-stranded DNA molecules that bind and inhibit human thrombin. Nature 355: 564-566, 1992

46. Lancellotti S and De Cristofaro R: Nucleotide-derived thrombin inhibitors: a new tool for an old issue. Cardiovasc Hematol Agents Med Chem 7: 19-28, 2009.

47. White R, Rusconi C, Scardino E, et al: Generation of species cross-reactive aptamers using 'toggle' SELEX. Mol Ther 4: 567-573, 2001.

48. Mazurov AV, Titaeva EV, Khaspekova SG, et al: Characteristics of a new DNA aptamer, direct inhibitor of thrombin. Bull Exp Biol Med 150: 422-425, 2011.

49. Tasset DM, Kubik MF and Steiner W: Oligonucleotide inhibitors of human thrombin that bind distinct epitopes. J Mol Biol 272 688-698, 1997.

50. Bompiani KM, Monroe DM, Church FC and Sullenger BA A high affinity, antidote-controllable prothrombin and thrombin-binding RNA aptamer inhibits thrombin generation and thrombin activity. J Thromb Haemost 10: 870-880, 2012.

51. Nimjee SM, Rusconi CP, Harrington RA and Sullenger BA The potential of aptamers as anticoagulants. Trends Cardiovasc Med 15: 41-45, 2005.

52. van de Locht A, Lamba D, Bauer M, et al: Two heads are better than one: crystal structure of the insect derived double domain Kazal inhibitor rhodniin in complex with thrombin. EMBO J 14: 5149-5157, 1995.

53. Markwardt F: The comeback of hirudin - an old-established anticoagulant agent. Folia Haematol Int Mag Klin Morphol Blutforsch 115: 10-23, 1988.

54. Salzet M: Leech thrombin inhibitors. Curr Pharm Des 8: 493-503, 2002

55. Strube KH, Kröger B, Bialojan S, Otte $\mathrm{M}$ and Dodt J: Isolation, sequence analysis and cloning of haemadin. An anticoagulant peptide from the Indian leech. J Biol Chem 268: 8590-8595, 1993.

56. Markwardt F: State-of-the-Art Review: antithrombotic agents from hematophagous animals. Clin Appl Thromb Hemost 2 : 75-82, 1996.

57. Salzet M, Chopin V, Baert J, Matias I and Malecha J: Theromin, a novel leech thrombin inhibitor. J Biol Chem 275: 30774-30780, 2000.

58. Francischetti IM, Valenzuela JG and Ribeiro JM: Anophelin: kinetics and mechanism of thrombin inhibition. Biochemistry 38 : 16678-16685, 1999.

59. Waidhet-Kouadio P, Yuda M, Ando K and Chinzei Y: Purification and characterization of a thrombin inhibitor from the salivary glands of a malarial vector mosquito, Anopheles stephensi. Biochim Biophys Acta 1381: 227-233, 1998

60. Watanabe RM, Soares TS, Morais-Zani K, et al: A novel trypsin Kazal-type inhibitor from Aedes aegypti with thrombin coagulant inhibitory activity. Biochimie 92: 933-939, 2010.
61. Soares TS, Watanabe RM, Tanaka-Azevedo AM, et al: Expression and functional characterization of boophilin, a thrombin inhibitor from Rhipicephalus (Boophilus) microplus midgut. Vet Parasitol: 521-528, 2012.

62. Macedo-Ribeiro S, Almeida C, Calisto BM, et al: Isolation, cloning and structural characterisation of boophilin, a multifunctional Kunitz-type proteinase inhibitor from the cattle tick. PLoS One 3: e1624, 2008.

63. Ciprandi A, de Oliveira SK, Masuda A, Horn F and Termignoni C: Boophilus microplus: Its saliva contains microphilin, a small thrombin inhibitor. Exp Parasitol 114: 40-46, 2006.

64. Liao M, Zhou J, Gong H, et al: Hemalin, a thrombin inhibitor isolated from a midgut cDNA library from the hard tick Haemaphysalis longicornis. J Insect Physiol 55: 165-173, 2009.

65. Iwanaga S, Okada M, Isawa H, Morita A, Yuda M and Chinzei Y: Identification and characterization of novel salivary thrombin inhibitors from the ixodidae tick, Haemaphysalis longicornis. Eur J Biochem 270: 1926-1934, 2003.

66. Noeske-Jungblut C, Haendler B, Donner P, Alagon A, Possani L and Schleuning WD: Triabin, a highly potent exosite inhibitor of thrombin. J Biol Chem 270: 28629-28634, 1995.

67. Campos I, Amino R, Sampaio C, et al: Infestin, a thrombin inhibitor present in Triatoma infestans midgut, a Chagas' disease vector: gene cloning, expression and characterization of the inhibitor. Insect Biochem Mol Biol 32: 991-997, 2002.

68. Araujo R, Campos I, Tanaka A, et al: Brasiliensin: a novel intestinal thrombin inhibitor from Triatoma brasiliensis (Hemiptera: Reduviidae) with an important role in blood intake. Int J Parasitol 37: 1351-1358, 2007.

69. Mende K, Petoukhova O, Koulitchkova V, et al: Dipetalogastin, a potent thrombin inhibitor from the blood-sucking insect Dipetalogaster maximus. Eur J Biochem 266: 583-590, 1999.

70. Osipov AV, Filkin SY, Makarova YV, Tsetlin VI and Utkin YN: A new type of thrombin inhibitor, noncytotoxic phospholipase A2, from the Naja haje cobra venom. Toxicon 55: 186-194, 2010.

71. Arocas V, Zingali RB, Guillin MC, Bon C and Jandrot-Perrus M: Bothrojaracin: a potent two-site-directed thrombin inhibitor. Biochemistry 35: 9083-9089, 1996

72. Yang X, Wang Y, Lu Z, et al: A novel serine protease inhibitor from the venom of Vespa bicolor Fabricius. Comp Biochem Physiol B Biochem Mol Biol 153: 116-120, 2009.

73. Lu X, Ma Y, Wu J and Lai R: Two serine protease inhibitors from the skin secretions of the toad, Bombina microdeladigitora. Comp Biochem Physiol B Biochem Mol Biol 149: 608-612, 2008.

74. Liu L, Ma H, Yang N, et al: A series of natural flavonoids as thrombin inhibitors: structure-activity relationships. Thromb Res 126: e365-e378, 2010.

75. Doljak B, Cateni F, Anderluh M, Procida G, Zilic J and Zacchigna M: Glycerolipids as selective thrombin inhibitors from the fungus Stereum hirsutum. Drug Dev Ind Pharm 32: 635-643, 2006

76. Li NG, Song SL, Shen MZ, et al: Mannich bases of scutellarein as thrombin-inhibitors: design, synthesis, biological activity and solubility. Bioorg Med Chem 20: 6919-1923, 2012.

77. Anas AR, Kisugi T, Umezawa T, et al: Thrombin inhibitors from the freshwater cyanobacterium Anabaena compacta. J Nat Prod 75: 1546-1552, 2012

78. Hanessian S, Therrien E, Zhang J, et al: From natural products to achiral drug prototypes: potent thrombin inhibitors based on P2/P3 dihydropyrid-2-one core motifs. Bioorg Med Chem Lett 19: 5429-5432, 2009.

79. Martin JA, Parekh P, Kim Y, et al: Selection of an aptamer antidote to the anticoagulant drug bivalirudin. PLoS One 8: e57341, 2013.

80. Hon SF, Li HL and Cheng PW: Use of direct thrombin inhibitor for treatment of cerebral venous thrombosis. J Stroke Cerebrovasc Dis 21: e11-e15, 2012.

81. Moshfeghi AA and Puliafito CA: Pegaptanib sodium for the treatment of neovascular age-related macular degeneration. Expert Opin Investig Drugs 14: 671-682, 2005.

82. Ku SK, Kim TH and Bae JS: Anticoagulant activities of persicarin and isorhamnetin. Vascul Pharmacol 58: 272-279, 2013.

83. Robert S, Baccelli C, Devel P, Dogné JM and Quetin-Leclercq J: Effects of leaf extracts from Croton zambesicus Müell. Arg. on hemostasis. J Ethnopharmacol 128: 641-648, 2010. 